\title{
Circulating Metabolites of the Human Immunodeficiency Virus Protease Inhibitor Nelfinavir in Humans: Structural Identification, Levels in Plasma, and Antiviral Activities
}

\author{
KANYIN E. ZHANG, ${ }^{1 *}$ ELLEN WU, ${ }^{1}$ AMY K. PATICK, ${ }^{1}$ BRADLEY KERR,${ }^{1}$ MARK ZORBAS, ${ }^{1}$ \\ ANGELA LANKFORD,${ }^{1}$ TAKUO KOBAYASHI, ${ }^{2}$ YUKI MAEDA, ${ }^{2}$ BHASKER SHETTY,${ }^{1}$ \\ AND STEPHANIE WEBBER ${ }^{1}$ \\ Pfizer Global Research and Development, La Jolla, California, ${ }^{1}$ and Central Pharmaceutical Research Institute, \\ Japan Tobacco Inc., Osaka 569, Japan ${ }^{2}$
}

Received 3 July 2000/Returned for modification 22 October 2000/Accepted 23 December 2000

\begin{abstract}
Nelfinavir mesylate (Viracept, formally AG1343) is a potent and orally bioavailable human immunodeficiency virus (HIV) type 1 (HIV-1) protease inhibitor $\left(K_{i}=2 \mathrm{nM}\right)$ and is being widely prescribed in combination with HIV reverse transcriptase inhibitors for the treatment of HIV infection. The current studies evaluated the presence of metabolites circulating in plasma following the oral administration of nelfinavir to healthy volunteers and HIV-infected patients, as well as the levels in plasma and antiviral activities of these metabolites. The results showed that the parent drug was the major circulating chemical species, followed in decreasing abundance by its hydroxy-t-butylamide metabolite (M8) and 3'-methoxy-4' -hydroxynelfinavir (M1). Antiviral assays with HIV-1 strain RF-infected CEM-SS cells showed that the 50\% effective concentrations $\left(\mathrm{EC}_{50}\right)$ of nelfinavir, $\mathrm{M8}$, and $\mathrm{M1}$ were 30,34 , and $151 \mathrm{nM}$, respectively, and that the corresponding $\mathrm{EC}_{50}$ against another HIV-1 strain, IIIB, in MT-2 cells were 60, 86, and 653 nM. Therefore, apparently similar in vitro antiviral activities were demonstrated for nelfinavir and M8, whereas an approximately 5- to 11-fold-lower level of antiviral activity was observed for M1. The active metabolite, M8, showed a degree of binding to human plasma proteins similar to that of nelfinavir (ca. 98\%). Concentrations in plasma of nelfinavir and its metabolites in $10 \mathrm{HIV}$-positive patients receiving nelfinavir therapy (750 $\mathrm{mg}$ three times per day) were determined by a liquid chromatography tandem mass spectrometry assay. At steady state (day 28), the mean plasma nelfinavir concentrations ranged from 1.73 to $4.96 \mu \mathrm{M}$ and the M8 concentrations ranged from 0.55 to $1.96 \mu \mathrm{M}$, whereas the M1 concentrations were low and ranged from 0.09 to $0.19 \mu \mathrm{M}$. In conclusion, the findings from the current studies suggest that, in humans, nelfinavir forms an active metabolite circulating at appreciable levels in plasma. The active metabolite M8 may account for some of the antiviral activity associated with nelfinavir in the treatment of HIV disease.
\end{abstract}

The therapeutic treatment of human immunodeficiency virus (HIV) infection had begun to show dramatic improvements since the introduction of HIV protease inhibitors $(5,6,8,11)$. In controlled clinical trials, the triple-drug combination therapy consisting of two HIV reverse transcriptase (RT) inhibitors and a protease inhibitor significantly reduced the plasma HIV RNA levels to below the detection limit of 50 to 500 copies $/ \mathrm{ml}$ in a high percentage of patients in a sustained manner $(6,11$, 24) and helped to recover $\mathrm{CD}^{+}$cell counts in some patients $(8,20,24)$. This strategy, which simultaneously targets two critical viral enzymes - the RT at the early stage of viral reproduction and the protease vital for the maturation of infectious virus-has proven to be a powerful weapon in combating HIV infection (19).

Nelfinavir mesylate $\left\{\right.$ Viracept; $\left[3 S-\left(3 R^{*}, 4 \mathrm{a} R^{*}, 8 \mathrm{a} R^{*}, 2^{\prime} S^{*}\right.\right.$, $\left.\left.3^{\prime} S^{*}\right)\right]-2-\left(2^{\prime}\right.$-hydroxy-3' -phenylthiomethyl-4' -aza-5' -oxo-5' $-\left(2^{\prime \prime}-\right.$ methyl- $3^{\prime \prime}$-hydroxy-phenyl)-decahydroisoquinoline-3- $N$ - $t$-butylcarboxamide methanesulfonic acid\} is a potent and orally available HIV protease inhibitor that has been shown in phase

\footnotetext{
* Corresponding author. Present address: Drug Metabolism and Pharmacokinetics, Merck Research Laboratories-San Diego, 505 Coast Blvd. South, Suite 300, La Jolla, CA 92037. Phone: (858) 4525892, ext. 488. Fax: (858) 452-9279. E-mail: kanyin_zhang@merck .com.
}

III controlled clinical trials to significantly reduce viral load and increase $\mathrm{CD} 4{ }^{+}$cell counts in patients when used in combination with RT inhibitors (16-18). This agent is currently being widely prescribed as part of triple-drug combination therapy for the treatment of HIV infection.

A critical aspect for the success of anti-HIV therapy using protease inhibitors is to maintain plasma drug concentrations at levels high enough such that the free drug concentrations, i.e., unbound to plasma proteins such as $\alpha_{1}$-acid glycoprotein, exceed what is necessary to significantly inhibit viral replication, as measured by, e.g., antiviral $90 \%$ effective concentrations $\left(\mathrm{EC}_{90}\right)(14)$. High and sustained drug concentrations ensure the maximum suppression of viral replication and minimize the emergence of drug-resistant viral strains $(3,11,12$, 15). Working against the desired high drug concentrations is the metabolic clearance of the protease inhibitors, which has been shown to be the principal elimination route $(2,7,9,10$, $13)$; in some instances, e.g., saquinavir, its clearance has been shown to limit the clinical use of the agent $(4,10,22,23)$. In other therapeutic areas, however, it is not uncommon for one or more metabolites to be retained in the systemic circulation and to contribute to or alter the pharmacological activity associated with the administration of the parent drug (25). Thus, a series of studies were conducted to characterize nelfinavir metabolites in plasma from healthy volunteers and HIV-posi- 
tive patients treated with nelfinavir mesylate. This report describes the results of these studies, including the structural elucidation, determination of concentrations in plasma, and antiviral activity testing of nelfinavir metabolites found in the systemic circulation of humans.

\section{MATERIALS AND METHODS}

Materials. $\left[{ }^{14} \mathrm{C}\right]$ nelfinavir mesylate capsules (lot AG1343-598.18A) were manufactured by Agouron Pharmaceuticals, Inc. Each capsule contained $75 \mathrm{mg}$ of nelfinavir mesylate, which included $9.89 \mu \mathrm{Ci}$ of $\left[{ }^{14} \mathrm{C}\right]$ nelfinavir mesylate and thus afforded a specific radioactivity of $0.1355 \mu \mathrm{Ci} / \mathrm{mg}$ or $76.83 \mu \mathrm{Ci} / \mathrm{mmol}$. $\left[{ }^{14} \mathrm{C}\right]$ nelfinavir mesylate was synthesized by Amersham International plc, Buckinghamshire, United Kingdom (benzamide carbonyl- ${ }^{14} \mathrm{C}$; batch CFQ9240; specific activity $=33.1 \mu \mathrm{Ci} / \mathrm{mg}$ or $18,767.7 \mu \mathrm{Ci} / \mathrm{mmol}$; radiochemical purity $=99.6 \%$, as determined by high-pressure liquid chromatography [HPLC]). Inactive ingredients in the capsules (hard gelatin, size 0, brown opaque) included the following: Gelucire 44/14 (saturated polyglycolized glycerides); Imwitor 742 (mono- and diglycerides); Cremophor EL (polyoxyl 35 castor oil, NF); propylene glycol, USP; and ethanol, USP. Nelfinavir metabolites AG1365 (M1), AG1402 (M8), AG1361A (M11), and AG1361B (M10) were synthesized by Agouron Pharmaceuticals. $\left[{ }^{14} \mathrm{C}\right] \mathrm{AG} 1402$ mesylate was synthesized by Amersham International ( $S$-phenyl-U- ${ }^{14} \mathrm{C}$; batch CFQ10100; specific activity $=34.1 \mu \mathrm{Ci} / \mathrm{mg}$ or $19,880.3$ $\mu \mathrm{Ci} / \mathrm{mmol}$; radiochemical purity $=99.5 \%$, as determined by HPLC). Scintillation cocktail (Ultima-Gold) was purchased from Beckman Instruments, Inc. (Fullerton, Calif.). Reagents used in the extraction and HPLC analysis of samples were as follows: acetonitrile (AcN), methanol (MeOH), and formic acid (all of HPLC grade; Fisher Scientific, Pittsburgh, Pa.). Human serum and plasma used in the analytical assays and protein binding studies were obtained from Sigma Chemical Co. (St. Louis, Mo.).

Studies with healthy volunteers. The volunteer single-dose radiolabeled nelfinavir study was conducted at GFI Pharmaceutical Services, Inc. (Evansville, Ind.) according to Agouron Pharmaceuticals protocol AG1343-527. Briefly, four healthy male volunteers were enrolled in this study. Each subject received 10 capsules of $\left[{ }^{14} \mathrm{C}\right]$ nelfinavir mesylate (750-mg and $98.9-\mu \mathrm{Ci}$ total doses) orally with $12 \mathrm{oz}$ of water within $10 \mathrm{~min}$ after the completion of a standard, low-fat breakfast. Blood samples were drawn predose and postdose at $0.25,0.5,1,1.5,2,2.5,3,4$, $6,8,12,24,36,48,72,96,120,144$, and $168 \mathrm{~h}$; plasma was obtained immediately after centrifugation of the blood and stored at $-20^{\circ} \mathrm{C}$ until analysis.

Metabolite identification. Plasma samples from each individual were pooled between 2.5 and $4 \mathrm{~h}$ and between 6 and $8 \mathrm{~h}(1 \mathrm{ml}$ each). Pooled samples were slowly added to 3 volumes of a mixture of $\mathrm{AcN}$ and $\mathrm{MeOH}$ at 2:1 during vortexing to precipitate plasma proteins. Upon centrifugation, protein pellets were washed twice with 2 volumes of an $\mathrm{AcN}-\mathrm{MeOH}(2: 1)$ mixture. An aliquot of the last wash (10\% by volume) was checked for radioactivity and was found to be near the background level. All extracts were combined, and an aliquot (5\% by volume) was used to count for radioactivity to calculate the extraction recovery. The combined supernatants were evaporated to dryness under nitrogen at $40^{\circ} \mathrm{C}$. When dried residues were reconstituted in a water-AcN (80:20) mixture, they were found to contain large amounts of lipid. Therefore, the samples were dried again, resuspended in 5\% trichloroacetic acid (TCA), and washed with hexane. Neither the hexane wash nor the TCA layer contained significant radioactivity. Therefore, the TCA supernatant was discarded and the residues were reconstituted in a water-AcN (80:20) mixture to afford a clear, lipid-free solution. Extraction recovery averaged $53 \%$, lower than expected, presumably due to the additional cleanup steps required to remove the lipids. Aliquots of the reconstituted extracts were injected into an LC-MS/MS system for analysis.

The liquid chromatography tandem mass spectrometry (LC-MS/MS) instruments were set up in the following sequence: an HPLC system (HP1090), a narrow-bore column (Prodigy ODS2; 2 by $150 \mathrm{~mm}$ ), a radiochemical detector (Ramona 92 with a $110-\mu l$ solid cell), and a triple-quadrupole mass spectrometer (VG Quattro I) using an electrospray interface. The mobile phase contained $0.1 \%$ formic acid (A) and $\mathrm{AcN}$ (B). Gradient elution was programmed linearly from 10 to $50 \%$ B over $30 \mathrm{~min}$ at a flow rate of $300 \mu \mathrm{l} / \mathrm{min}$. Mass spectrometer conditions were set as follows: cone voltage $=55 \mathrm{~V}$, source temperature $=$ $100^{\circ} \mathrm{C}$, collision energy $=40 \mathrm{eV}$, and positive ion detection mode. To obtain molecular ion information, the mass spectrometer was operated in MS scan mode $(m / z 200$ to 1,000$)$; to obtain structural information, the instrument was operated in MS/MS (daughter ion) scan mode and the multiple selective reaction monitoring (MRM) detection mode. The scan rate was set at approximately 500 atomic mass units (AMU)/s, and a dwell time of $0.2 \mathrm{~s}$ was allocated for each MRM channel.
Total radioactivity in plasma and red blood cells. Aliquots $(1 \mathrm{ml})$ of plasma samples in duplicate were mixed with $15 \mathrm{ml}$ of scintillation cocktail and analyzed directly by liquid scintillation counting (LSC). Red blood cell samples were homogenized by stirring with a spatula, and duplicate aliquots (approximately $0.25 \mathrm{~g}$ ) were combusted in a Packard Oxidizer and analyzed by LSC. The total radioactive material in each sample was converted to micromolar equivalents of $\left[{ }^{14} \mathrm{C}\right]$ nelfinavir using a specific activity of $76.83 \mu \mathrm{Ci} / \mathrm{mmol}$.

HPLC assay for the determination of nelfinavir in human plasma. Plasma nelfinavir concentrations were determined by a published HPLC assay (27). Briefly, nelfinavir and its internal standard [6,7-dimethyl-2,3-di-(2-pyridyl)quinoxaline] were extracted from $250 \mu \mathrm{l}$ of human plasma with a mixture of ethyl acetate and $\mathrm{AcN}(90: 10, \mathrm{vol} / \mathrm{vol})$. Chromatography was performed on a reversephase $\mathrm{C}_{18}$ column, and the analytes were eluted with an isocratic mobile phase consisting of $58 \%$ phosphate buffer $(25 \mathrm{mM}$; pH 3.4$)$ and $42 \%$ AcN. Nelfinavir and the internal standard were detected via UV at $220 \mathrm{~nm}$. The assay was validated under Good Laboratory Practice (GLP) compliance over a concentration range of 30 to $10,000 \mathrm{ng} / \mathrm{ml}$ and was conducted at PPD Pharmaco, Richmond, Va.

Studies with HIV-positive patients. Studies with HIV-positive patients were conducted according to Agouron Pharmaceuticals protocol AG1343-503. Ten patients receiving nelfinavir mesylate therapy ( $750 \mathrm{mg}$ three times per day [TID]) were involved in the study. Blood samples were drawn on days 1 and 28 predose and postdose at $0.5,1,1.5,2,3,4,5,6$, and $8 \mathrm{~h}$. Plasma was obtained immediately after centrifugation of the blood and stored at $-20^{\circ} \mathrm{C}$ until analysis.

LC-MS/MS assay for the simultaneous determination of nelfinavir and two metabolites in human plasma. Concentrations in plasma of nelfinavir and its metabolites were determined by a validated LC-MS/MS assay. Briefly, an aliquot $(100 \mu \mathrm{l})$ of plasma was spiked with the internal standard (reserpine), adjusted to pH 10.5 with $\mathrm{NH}_{4} \mathrm{OH}$, and extracted with a mixture of ethyl acetate and $\mathrm{AcN}$ $(90: 10, \mathrm{vol} / \mathrm{vol})$. The extracts were evaporated to dryness, the residues were reconstituted in $200 \mu \mathrm{l}$ of the mobile phase, and an aliquot ( $15 \mu \mathrm{l})$ was analyzed by LC-MS/MS

The LC-MS/MS system consisted of an HP1090 HPLC system interfaced with a PE Sciex API III ${ }^{+}$triple-quadrupole mass spectrometer using Turbo IonSpray. Chromatography was performed on a reverse-phase $\mathrm{C}_{8}$ column (Javelin, $5 \mu \mathrm{m}, 2$ by $20 \mathrm{~mm}$; Keystone Scientific) at ambient temperature using an isocratic mobile phase containing $75 \% \mathrm{AcN}$ and $25 \%$ aqueous formic acid $(0.1 \%)$ at a flow rate of $250 \mu \mathrm{l} / \mathrm{min}$. Analytes were detected by MS/MS operating under MRM mode as follows: $\mathrm{m} / \mathrm{z} 568.4 \rightarrow 330.2$ for nelfinavir at approximately $2.7 \mathrm{~min}, \mathrm{~m} / \mathrm{z}$ $598.4 \rightarrow 360.2$ for M1 at approximately $2.7 \mathrm{~min}, \mathrm{~m} / \mathrm{z} 584.3 \rightarrow 467.0$ for M8 at approximately $2.0 \mathrm{~min}$, and $\mathrm{m} / \mathrm{z} 609.2 \rightarrow 397.4$ for the internal standard (reserpine) at approximately $2.5 \mathrm{~min}$.

Ratios of the peak areas of the analytes to those of the internal standard were used for quantitation, and the calibration curves were obtained by use of MacQuan software (PE Sciex) with least-squares linear regression analysis and weighted $\left(1 /\right.$ concentration $\left.^{2}\right)$ data. The equations obtained from the calibration curves were then used to calculate the concentration of each analyte in unknown and quality control samples.

The LC-MS/MS assay was validated with human plasma for nelfinavir, M1, and $\mathrm{M} 8$ over the concentration ranges of 20 to $3,000 \mathrm{ng} / \mathrm{ml}, 1$ to $1,000 \mathrm{ng} / \mathrm{ml}$, and 1 to $2,000 \mathrm{ng} / \mathrm{ml}$, respectively. The validation process included six calibration curves analyzed over 3 days, during which the intra- and interday precision and accuracy of the assay were assessed with plasma quality control samples prepared at low, middle, and high concentrations (six samples at each level for each day). The stability of the analytes was tested by subjecting the plasma to three freezethaw cycles and storage at room temperature for $24 \mathrm{~h}$. Assay validation and sample analyses were performed under GLP compliance at Covance Laboratories, Inc., Madison, Wis.

Pharmacokinetic parameters for studying AG1343-503 were obtained by noncompartmental analysis using the PCNONLIN program (Scientific Consulting Inc., Apex, N.C.) and included the following output: observed time to maximum concentration $\left(T_{\max }\right)$, observed maximum concentration $\left(C_{\max }\right)$, observed minimum concentration $\left(C_{\min }\right)$, and the area under the plasma concentration-time curve (AUC) from 0 to $8 \mathrm{~h}\left(\mathrm{AUC}_{0-8}\right)$. Statistical comparisons were made using Student's paired $t$ test.

Antiviral activity assay. Antiviral activities of nelfinavir metabolites were determined with CEM-SS and MT-2 cell lines infected with HIV type 1 (HIV-1) strains RF and IIIB, respectively. Both strains of virus were obtained from the AIDS Research and Reference Program, Division of AIDS, National Institute of Allergy and Infectious Disease, National Institutes of Health. The inhibitory effects of each agent on HIV-1 replication were measured by the microculture tetrazolium (MTT) dye reduction method (1). Test compounds were dissolved in dimethyl sulfoxide at a concentration of $40 \mathrm{mg} / \mathrm{ml}$ and then diluted 1:200 in 


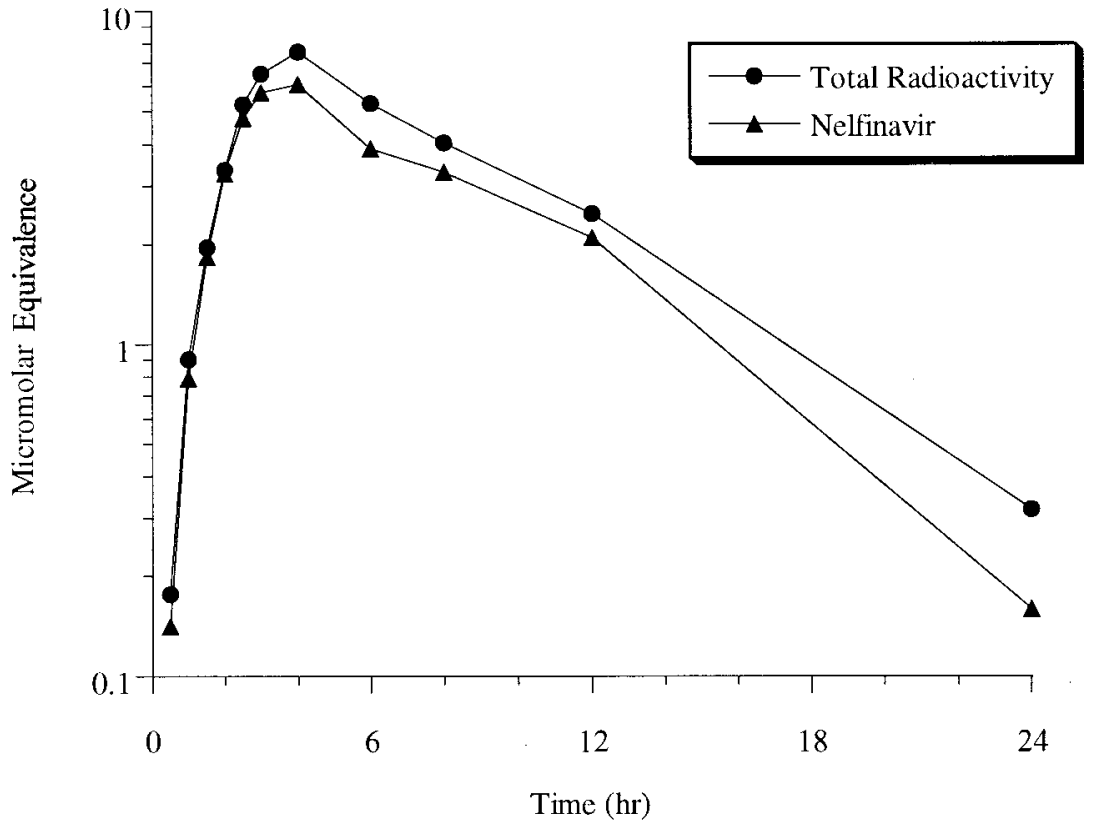

FIG. 1. Mean levels of total radioactivity and nelfinavir concentrations in plasma of healthy male volunteers $(n=4)$ following a 750 -mg oral dose of $\left[{ }^{14} \mathrm{C}\right]$ nelfinavir mesylate.

culture medium. From each diluted stock, an aliquot $(100 \mu \mathrm{l})$ was added to a 96-well plate, and serial half-log dilutions were prepared. In separate tubes, MT-2 cells and CEM-SS cells were infected with HIV-1 IIIB or HIV-1 RF at multiplicities of infection of 0.01 and 0.03 , respectively. Following a 4-h adsorption period, $100-\mu \mathrm{l}$ aliquots of infected or uninfected cells were added to the wells of the drug-containing plate to give a final concentration of $10^{4}$ cells/well. Six (CEM-SS cells) or 7 (MT-2 cells) days later, MTT $(5 \mathrm{mg} / \mathrm{ml})$ was added to test plates, and the amount of formazan produced was quantified spectrophotometrically at $570 \mathrm{~nm}$. Data were expressed as the percentage of formazan produced in drug-treated cells compared to that in control cells (uninfected, drug free). The $\mathrm{EC}_{50}$ was calculated as the concentration of drug that increased formazan production in infected, drug-treated cells to $50 \%$ that in control cells (uninfected, drug free). Cytotoxicity $\left(\mathrm{TC}_{50}\right)$ was calculated as the concentration of drug that decreased formazan production in uninfected, drug-treated cells to $50 \%$ that in control cells (uninfected, drug free). The therapeutic index (TI) in these cell lines was calculated by dividing the $\mathrm{TC}_{50}$ by the $\mathrm{EC}_{50}$.

Human serum protein binding. Human serum protein binding experiments were conducted using commercially obtained human serum in Teflon dialysis chambers (Spectrum Medical Industries, Inc., Houston, Tex.), each of which was separated into two compartments by a dialysis membrane with a molecular weight cutoff of 3,500. Radiolabeled nelfinavir or radiolabeled M8 was preincubated with human serum at room temperature for approximately $1 \mathrm{~h}$, and then an aliquot $(0.8 \mathrm{ml})$ of the spiked serum was placed in one side of the dialysis chamber. The opposite side of the dialysis membrane was filled with an equal volume of phosphate buffer $(0.13 \mathrm{M} ; \mathrm{pH}$ 7.4). The test materials were allowed to equilibrate overnight (approximately $16 \mathrm{~h}$ ) at $37^{\circ} \mathrm{C}$ with continuous end-over-end mixing; thereafter, an aliquot $(0.65 \mathrm{ml})$ from each side was used for counting by LSC. The fraction of unbound test material was calculated by dividing the radioactivity (in disintegrations per minute) on the buffer side by that on the serum side and multiplying the result by $100 \%$. Two experiments with triplicate measurements were performed at each concentration. To ensure that equilibrium was reached after $16 \mathrm{~h}$, control experiments were carried out with dialysis chambers in which either buffer or serum was placed on both sides. Statistical comparisons were made using Student's two-sample $t$ test.

\section{RESULTS}

Disposition of $\left[{ }^{14} \mathrm{C}\right]$ nelfinavir in human plasma. Following a single oral dose of $\left[{ }^{14} \mathrm{C}\right]$ nelfinavir to healthy subjects, the majority of radioactivity in plasma could be accounted for by the parent drug, as shown in Fig. 1. The AUC for nelfinavir represented $83 \%$ of that for total radioactivity; presumably, the remainder was attributable to nelfinavir metabolites. Red blood cells were found to contain very little radioactivity (data not shown).

Structural identification of nelfinavir metabolites. Due to the low level of radioactivity administered to the human subjects, no discrete radioactive peak could be detected in the plasma samples by a flowthrough radiochemical detector. Nevertheless, total ion chromatograms (TIC) $(\mathrm{m} / \mathrm{z} 200$ to 1,000) of plasma samples from all four subjects showed two distinct peaks: (i) the more abundant peak at approximately $21.9 \mathrm{~min}$, for which a full-scan mass spectrum displayed a major ion at $\mathrm{m} / \mathrm{z} 568$ and a minor ion at $\mathrm{m} / \mathrm{z} 598$, and (ii) a less abundant peak at $18.2 \mathrm{~min}$, for which a full-scan mass spectrum displayed a major ion at $m / z 584$. A representative sample from subject M01 (6- to 8-h pool) is illustrated in Fig. 2, which shows TIC and reconstructed ion chromatograms (RIC) at $m / z 568,584$, and 598. These ions correspond to the protonated molecules $\left(\mathrm{MH}^{+}\right)$of nelfinavir and two metabolites with increases in molecular weight of 16 amu (M8) and 30 amu (M1), respectively. M8 was a more polar metabolite, as it eluted earlier than nelfinavir on the reverse-phase column; M1 coeluted with nelfinavir. Also noticeable in the TIC were a series of peaks eluting between 10 and $15 \mathrm{~min}$ with a set of ions between $\mathrm{m} / \mathrm{z}$ 379 and $m / z 775$ in 44-amu increments (data not shown); these peaks were believed to arise from polymeric excipient materials in the drug formulation.

The product ion mass spectrum of the ion at $\mathrm{m} / \mathrm{z} 568$ confirmed that it was the parent drug nelfinavir (Fig. 3a). Although a clean product ion spectrum could not be obtained for M1 at $m / z 598$ due to its low abundance, the LC-MS/MS MRM trace at $m / z \quad 598 \rightarrow 360$ indicated that this metabolite was $3^{\prime}$ - 


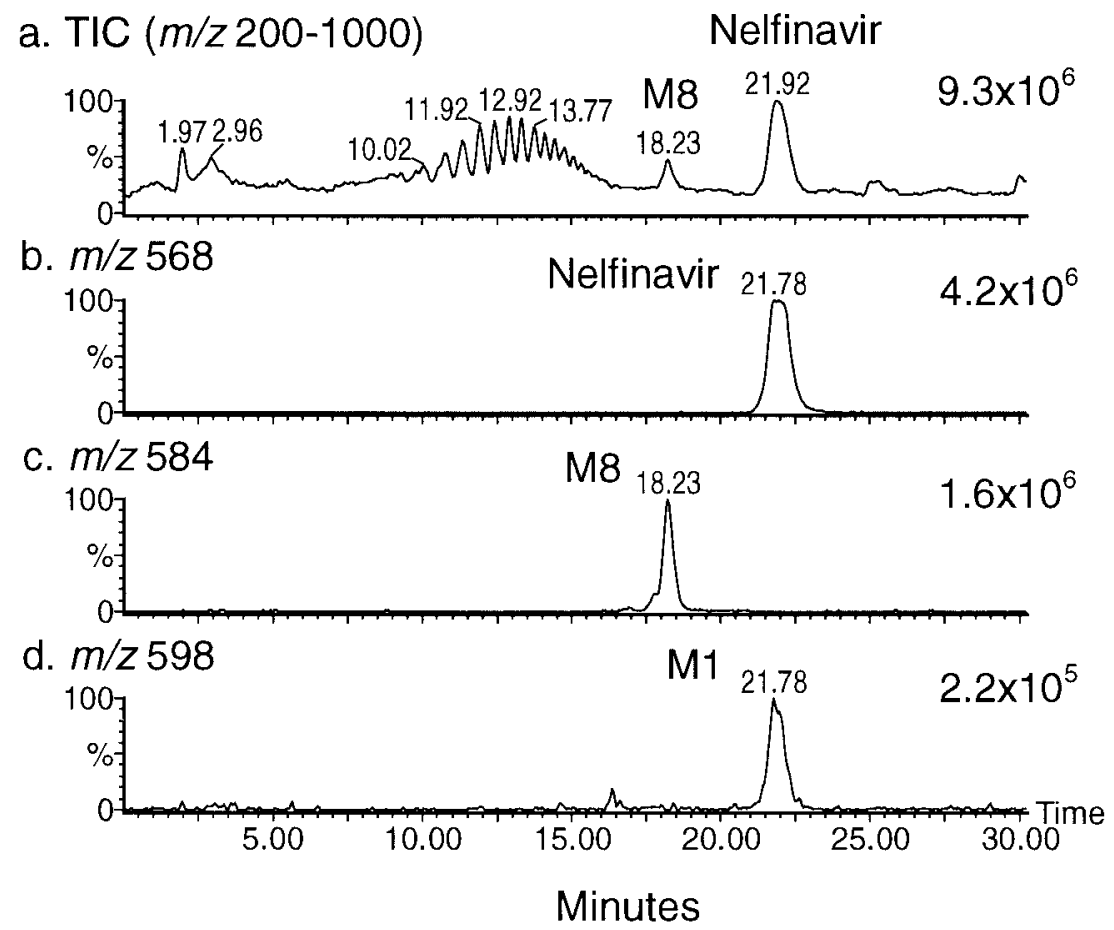

FIG. 2. LC-MS traces of a representative pooled (6- to 8-h) plasma sample from a healthy volunteer after administration of a 750-mg oral dose of nelfinavir mesylate. (a) TIC; (b to d) RIC.

methoxy-4'-hydroxynelfinavir, previously identified from rat bile by LC-MS/MS and nuclear magnetic resonance analysis and confirmed by comparison with the authentic standard, AG1365 (data not shown). The product ion mass spectrum of the ion at $m / z 584$ is shown in Fig. 3b; all three key fragment ions from the parent drug were preserved, specifically at $\mathrm{m} / \mathrm{z}$ 135, 330, and 467. These mass spectral features indicated that this metabolite was modified with a hydroxy group on the $t$-butamide group, and it was designated M8. The identity of M8 as nelfinavir hydroxy-t-butamide was confirmed later with the authentic standard, AG1402.

In addition to M1 and M8, two $S$-oxides of nelfinavir (M10 and M11) were detected in trace amounts by the LC-MS/MS MRM trace at $m / z 584 \rightarrow 251$; these spectral features matched the authentic $S$-oxide standards (AG1361B and AG1361A, respectively).

In vitro antiviral activity of nelfinavir metabolites. The antiviral activity and cytotoxicity of nelfinavir and its plasma metabolites were tested with CEM-SS cells infected with HIV-1 strain RF and MT-2 cells infected with HIV-1 strain IIIB; the results are summarized in Tables 1 and 2. In HIV-1-infected CEM-SS cells (Table 1), the $\mathrm{EC}_{50}$ for nelfinavir and metabolite M8 (AG1402) were 30.1 and $34.2 \mathrm{nM}$, respectively. Interestingly, M8 was less cytotoxic than nelfinavir to CEM-SS cells, resulting in an almost threefold-higher $\mathrm{TI}$ in this assay. In contrast, metabolite M1 (AG1365) showed $\mathrm{EC}_{50}$ fivefold higher than those of nelfinavir. In HIV-1-infected MT-2 cells (Table 2), the $\mathrm{EC}_{50}$ for nelfinavir was $60.2 \mathrm{nM}$ and the corresponding value for M8 (AG1402) was $85.6 \mathrm{nM}$. As in CEM-SS cells, M8 was also less cytotoxic than nelfinavir in MT-2 cells, resulting in an approximately sixfold-higher TI under these experimental conditions. As in the CEM-SS cell assay, M1 showed much higher $\mathrm{EC}_{50}$ (11-fold) than nelfinavir. Thus, an apparent similarity in antiviral activity was observed for nelfinavir and M8 (AG1402) against both HIV-1 RF and HIV-1 IIIB, whereas a 5- to 11-fold reduction in antiviral activity relative to that of nelfinavir was observed for M1 (AG1365). The data also indicated that M8 was less cytotoxic than either nelfinavir or M1 in these in vitro cell-based assays.

Concentrations of nelfinavir metabolites in human plasma. Concentrations of nelfinavir, M1, and M8 in plasma in humans were simultaneously determined by an LC-MS/MS assay, which was validated in the concentration ranges of 20 to 3,000 $\mathrm{ng} / \mathrm{ml}, 1$ to $1,000 \mathrm{ng} / \mathrm{ml}$, and 1 to $2,000 \mathrm{ng} / \mathrm{ml}$ for the three respective analytes. Over these concentration ranges, the assay was linear and accurately measured the concentrations of all three analytes within $10 \%$ deviation from the theoretical values; the reproducibility of the assay was within $15 \%$ for most standards.

Plasma samples obtained on days 1 and 28 from 10 HIVpositive patients who received nelfinavir mesylate therapy (750 mg TID) were analyzed by the LC-MS/MS assay, and the mean plasma concentration-time curves are shown in Fig. 4. The pharmacokinetic parameters calculated from these data are summarized in Table 3 . At steady state, the mean $C_{\max }$ and $C_{\text {min }}$ for nelfinavir were 4.96 and $1.73 \mu \mathrm{M}$, respectively. The steady-state $C_{\max }$ and $C_{\min }$ for M8 were 1.96 and $0.55 \mu \mathrm{M}$, and the corresponding values for M1 were 0.19 and $0.09 \mu \mathrm{M}$. Thus, M8 is the major circulating metabolite following the administration of nelfinavir to humans, as the $\mathrm{AUC}_{0-8}$ ratios of $\mathrm{M} 8$ to nelfinavir ranged from 0.27 to 0.39 . Statistical analysis of the pharmacokinetic parameters $\left(\mathrm{AUC}_{0-8 \mathrm{~h}}\right.$ and $\left.C_{\text {max }}\right)$ between 
a.
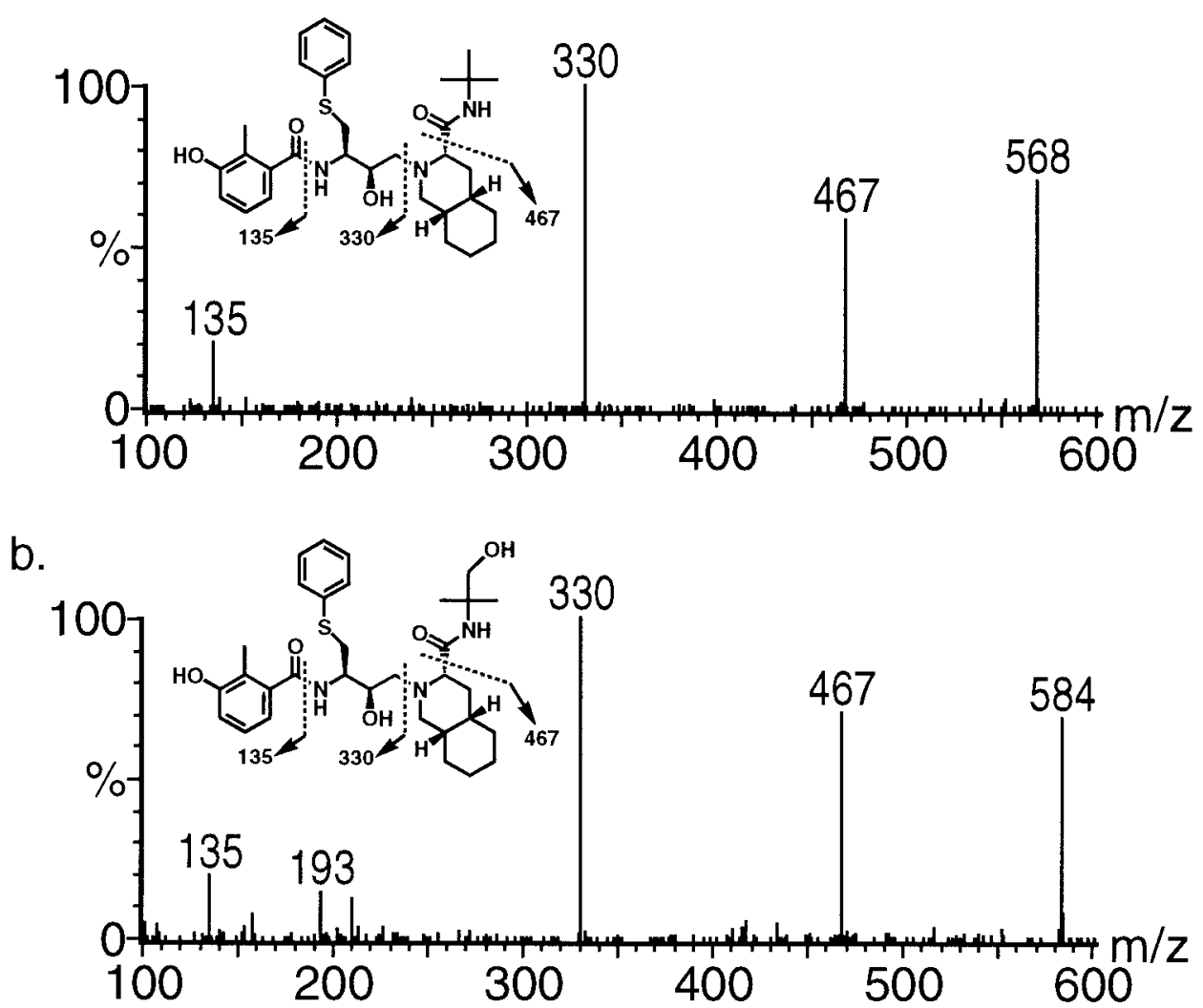

FIG. 3. Product ion mass spectra of nelfinavir (a) and M8 (b).

days 1 and 28 did not show any significant differences (Table 3 ); therefore, repeat administration of nelfinavir does not appear to induce its own metabolism, nor does there appear to be unexpected accumulation of either the parent drug or its metabolites.

Binding of nelfinavir metabolites to human serum proteins. Binding of nelfinavir and the active metabolite M8 to human serum proteins was determined in vitro by equilibrium dialysis, and the results are reported in Table 4. The metabolite showed a slightly lower degree of binding to human serum proteins than the parent drug, especially at the relevant therapeutic concentration $(2 \mu \mathrm{M})$. The experiment was also performed in a competitive fashion to mimic the in vivo situation, where both nelfinavir and M8 were present; the results did not show any significant increase in the percentage of unbound nelfinavir in the presence of up to $8 \mu \mathrm{M}$ M 8 or of unbound M8 in the presence of up to $8 \mu \mathrm{M}$ nelfinavir (data not shown).

TABLE 1. Antiviral activity and cytotoxicity of nelfinavir and its metabolites in acute infection of CEM-SS cells with HIV-1 RF

\begin{tabular}{lccr}
\hline Compound & $\mathrm{EC}_{50}(\mathrm{nM})$ & $\mathrm{TC}_{50}(\mu \mathrm{M})$ & $\mathrm{TI}$ \\
\hline Nelfinavir & 30.1 & 28.9 & 960 \\
M1 (AG1365) & 150.8 & 26.1 & 173 \\
M8 (AG1402) & 34.2 & 96.6 & 2,825 \\
\hline
\end{tabular}

${ }^{a}$ Antiviral efficacy was determined by measuring MTT reduction 6 days after infection. Results represent the mean of two experiments.

\section{DISCUSSION}

Following oral administration of nelfinavir mesylate to either healthy volunteers as a single dose or to HIV-infected patients as multiple doses, nelfinavir was the major circulating species in plasma, with several metabolites as minor components. The most abundant circulating metabolite, M8 (AG1402), involved the hydroxylation of nelfinavir on the $t$ butylamide group, and the less abundant metabolite M1 (AG1365) presumably resulted from 4'-hydroxylation on the benzamide moiety to form a catechol intermediate followed by methylation at the $3^{\prime}$ position. Sulfur oxidation of nelfinavir afforded two diastereomers (M10 and M11) in approximately equal abundances; however, both were present at such low levels that they were barely detectable by even the most sensitive mode of LC-MS/MS detection. Other biotransformation products involving hydroxylation of various structural moieties on the drug molecule were not detected in human plasma, although some were found as major metabolites in feces as well

TABLE 2. Antiviral activity and cytotoxicity of nelfinavir and its metabolites in acute infection of MT-2 cells with HIV-1 IIIB ${ }^{a}$

\begin{tabular}{lccr}
\hline Compound & $\mathrm{EC}_{50}(\mathrm{nM})$ & $\mathrm{TC}_{50}(\mu \mathrm{M})$ & \multicolumn{1}{c}{$\mathrm{TI}$} \\
\hline Nelfinavir & 60.2 & 11.1 & 184 \\
M1 (AG1365) & 653.3 & 13.3 & 20 \\
M8 (AG1402) & 85.6 & 92.6 & 1,082
\end{tabular}

${ }^{a}$ Antiviral efficacy was determined by measuring MTT reduction 7 days after infection. Results represent the mean of two experiments. 


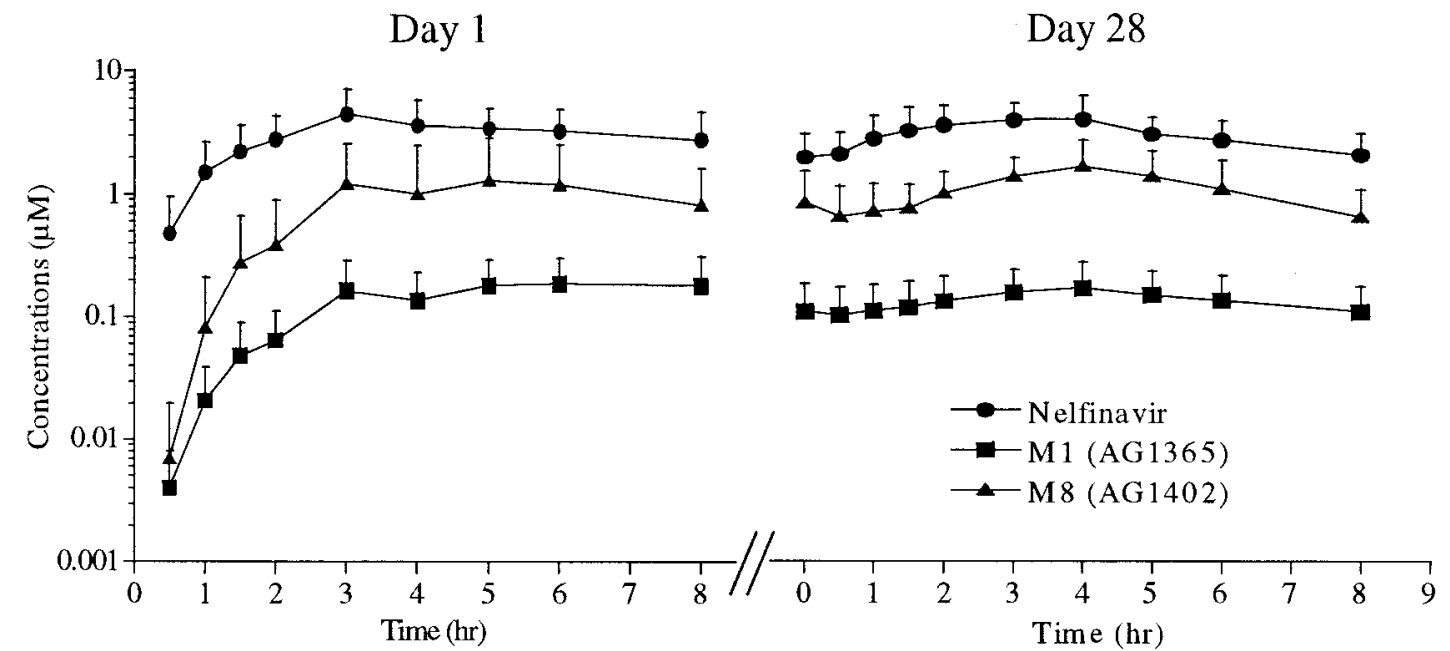

FIG. 4. Concentrations of nelfinavir, M1, and M8 in plasma following administration of a single oral dose (day 1) and multiple oral doses (day 28) of nelfinavir mesylate (750 mg TID) to $10 \mathrm{HIV}$-positive patients. Data are means \pm standard deviations.

as in human liver microsomal in vitro studies $(26,28)$. Figure 5 summarizes the biotransformation pathways that lead to the two main circulating metabolites in human plasma.

Having identified these metabolites in human plasma samples, we synthesized authentic standards to confirm their identity, to test for antiviral activity, and to use as analytical standards for their quantitative determination in human plasma. Subsequently, it was found that one of the metabolites, M8, exhibited antiviral activity similar to that of the parent drug in cell protection assays in vitro. Subsequent computer modeling experiments conducted at the Crystallography Department at Agouron Pharmaceuticals suggested that the hydroxy-t-butyl group of M8 can form an additional hydrogen bond with aspartate 30 of the HIV protease enzyme; however, this gain in binding energy could be offset by desolvation of the same hydroxy group while it gains access to the active site of the protease enzyme. This interpretation is consistent with the observation that M8 and nelfinavir exhibit similar in vitro antiviral activities.

Equilibrium dialysis studies indicated that the binding of M8 to human serum proteins was 97.6 to $97.9 \%$, a value comparable to that of nelfinavir (98.3 to $98.6 \%$ ). Therefore, the metabolite M8 apparently has antiviral activity similar to that of the parent drug nelfinavir. Further in vitro experiments may be necessary to demonstrate any additive, synergistic, or an- tagonistic relationship that may exist between nelfinavir and M8.

Quantitative analysis of nelfinavir metabolites in the plasma of HIV-infected patients indicated that the active metabolite M8 reached significant levels, such that at steady state, the $C_{\max }$ and $C_{\min }$ ratios of M8 to nelfinavir were 0.43 and 0.34 , respectively, and the corresponding $\mathrm{AUC}_{0-8}$ ratio was 0.39. In contrast, the less active metabolite, M1, was present at much lower levels, such that at steady state, the $C_{\max }$ and $C_{\min }$ ratios of M1 to nelfinavir were 0.04 and 0.05 , respectively, and the corresponding $\mathrm{AUC}_{0-8}$ ratio was 0.05 .

Ritonavir is the only other HIV protease inhibitor that has been reported to form an active metabolite (M2), although it is present at low levels in HIV-infected patient plasma (9). Thus, nelfinavir is unique among the marketed HIV protease inhibitors in that it is the only agent that produces an active metabolite at levels in plasma which are significant enough to contribute to the overall antiviral activity.

The success of chemotherapy for HIV infection is highly dependent on the maintenance of drug levels. The maintenance of adequate levels of an antiviral agent is critical to achieving maximal viral suppression and to minimizing the emergence of drug-resistant strains. During nelfinavir treatment, due to the presence of appreciable levels of the active and potentially equipotent metabolite M8, measurement of

TABLE 3. Pharmacokinetic parameters for nelfinavir and its metabolites in $10 \mathrm{HIV}$-positive patients receiving nelfinavir treatment at $750 \mathrm{mg}$ TID $^{a}$

\begin{tabular}{clllll}
\hline Day & \multicolumn{1}{c}{ Drug } & \multicolumn{1}{c}{$C_{\max }(\mu \mathrm{M})$} & $T_{\max }(\mathrm{h})$ & $\mathrm{AUC}_{0-8}(\mu \mathrm{M} \cdot \mathrm{h})$ & $C_{\min }(\mu \mathrm{M})$ \\
\hline 1 & Nelfinavir & $5.04 \pm 2.56$ & $3.9 \pm 1.7$ & $23.2 \pm 10.7$ \\
& M1 & $0.24 \pm 0.13(0.05)$ & $5.7 \pm 1.8$ & $1.02 \pm 0.54(0.04)$ & \\
& M8 & $1.73 \pm 1.62(0.33)$ & $5.5 \pm 1.6$ & $6.62 \pm 7.15(0.27)$ & \\
28 & & & & $24.5 \pm 10.2$ & $1.73 \pm 1.05$ \\
& Nelfinavir & $4.96 \pm 2.22$ & $2.9 \pm 1.0$ & $1.11 \pm 0.65(0.05)$ & $0.09 \pm 0.07(0.05)$ \\
& M1 & $0.19 \pm 0.10(0.04)$ & $3.4 \pm 1.4$ & $9.04 \pm 4.87(0.39)$ & $0.55 \pm 0.37(0.34)$ \\
\hline
\end{tabular}

\footnotetext{
${ }^{a}$ Data are presented as means and standard deviations. Statistical comparisons for all corresponding values on days 1 and 28 did not show any significance differences. Numbers in parentheses are the mean ratio of the concentration of a metabolite (M1 or M8) to that of nelfinavir, measured in the same patient.
} 


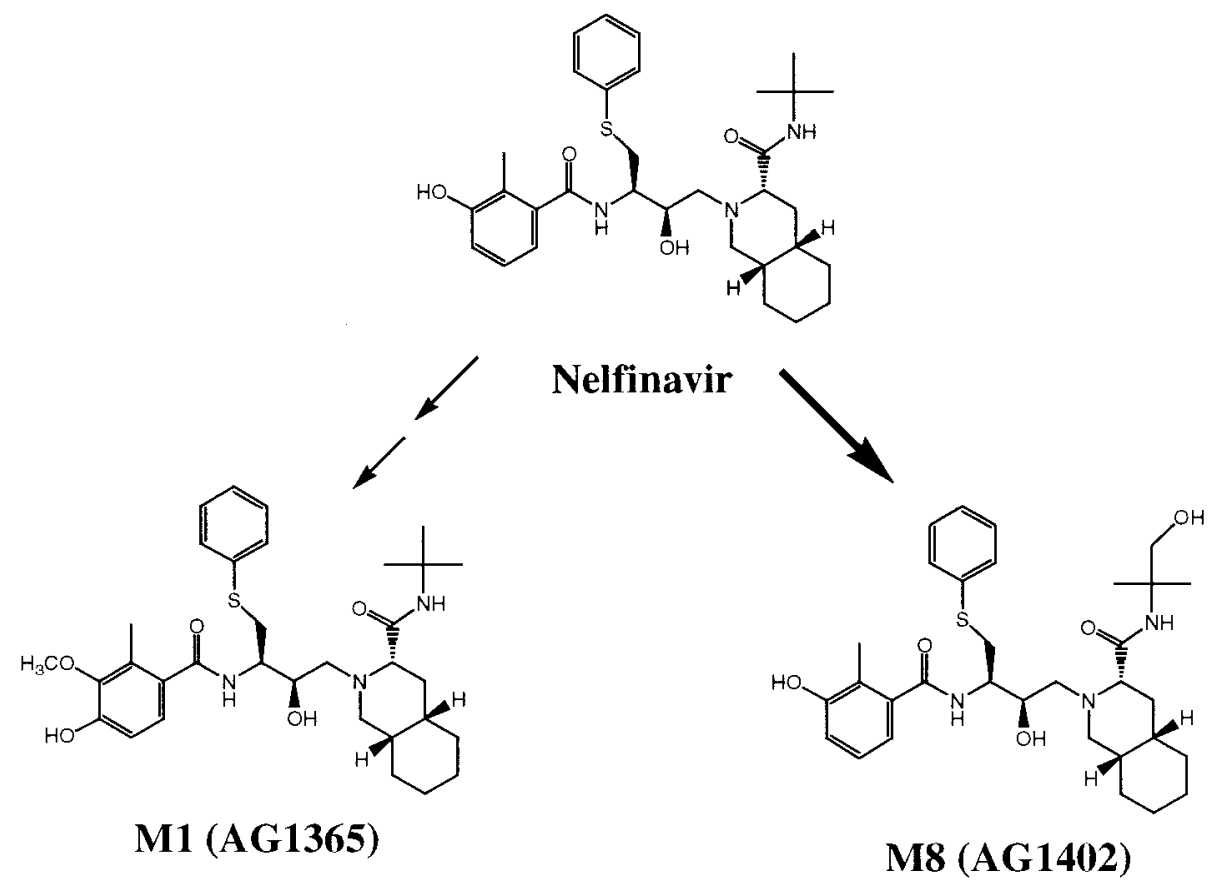

FIG. 5. Biotransformation pathways for nelfinavir that lead to circulating metabolites in human plasma. The bold arrow indicates the major pathway.

nelfinavir levels alone may underestimate the antiviral effects of this agent. The findings from the current study suggest that the active metabolite may account for some of the antiviral activity associated with nelfinavir in the treatment of HIV disease.

Results from analyses of the metabolites excreted from healthy human subjects indicated that hydroxylation of $t$-butylamide is one of the three major metabolic pathways responsible for the clearance of nelfinavir (28). In vitro experiments using human liver microsomes and cDNA-expressed cytochrome P450 (CYP) isoforms have shown that CYP2C19 is responsible for the formation of M8, whereas CYP3A4 mediates two other prominent metabolic pathways for nelfinavir (26). CYP2C19 is a genetically polymorphic enzyme; $2 \%$ of the Caucasian population and $20 \%$ of the Asian population are poor metabolizers (21). In the case of nelfinavir metabolism, a phenotypically poor metabolizer of CYP2C19 who forms little or no M8 will likely exhibit elevated parent drug concentrations because M8 formation is an important elimination path-

TABLE 4. Binding of nelfinavir and its active metabolite (M8) to human serum

\begin{tabular}{ccc}
\hline \multirow{2}{*}{$\begin{array}{c}\text { Concn } \\
(\mu \mathrm{M})\end{array}$} & \multicolumn{2}{c}{$\%$ of the following drug unbound: } \\
\cline { 2 - 3 } & Nelfinavir & $\begin{array}{c}\text { M8 } \\
\text { (AG1402) }\end{array}$ \\
\hline 1 & Not determined & $2.4 \pm 0.4^{a}$ \\
2 & $1.7 \pm 0.1$ & $2.1 \pm 0.1^{a}$ \\
20 & $1.4 \pm 0.1^{b}$ & $2.4 \pm 0.1^{a}$ \\
\hline
\end{tabular}

${ }^{a}$ Statistically higher percentage unbound compared to the results for nelfinavir at $2 \mu \mathrm{M}(P<0.05)$.

${ }^{b}$ Historical result obtained at $10 \mu \mathrm{g} / \mathrm{ml}(17.6 \mu \mathrm{M})$. way for the drug. However, since the two chemical species are apparently similar with respect to antiviral activity, the overall antiviral efficacy would not be expected to change significantly due to alterations in this CYP2C19-mediated metabolic pathway. This hypothesis has been confirmed clinically in that no significant differences were observed in the antiviral responses achieved in two groups of patients likely to be poor and extensive CYP2C19 metabolizers who formed little or no M8 and appreciable levels of M8, respectively (H. M. Zhang, Y. K. Pithavala, C. A. Lee, J. H. Lillibridge, E. Y. Wu, T. M. Sandoval, R. G. Daniels, and B. M. Kerr, Abstr. 12th Int. Symp. Microsomes Drug Oxidations, abstr. 264, 1998).

\section{ACKNOWLEDGMENTS}

We thank Rasmy Talaat, Lisa Moger, and Craig Wagner from Covance Laboratories for the analysis of nelfinavir metabolites and Krzysztof Appelt from Agouron Pharmaceuticals for computer modeling and insightful discussion on the binding of nelfinavir and the M8 metabolite to the HIV protease.

\section{REFERENCES}

1. Alley, C. M., D. A. Scudiero, A. Monks, L. M. Hursey, J. M. Czerwinski, D. L. Fine, B. J. Abbott, J. G. Mayo, R. H. Shoemaker, and M. R. Boyd. 1988. Feasibility of drug screening with panels of human tumor cell lines using microculture tetrazolium assay. Cancer Res. 48:589-601.

2. Balani, S. K., E. J. Woolf, V. L. Hoagland, G. M. Sturgill, P. J. Deutsch, K. C. Yeh, and J. H. Lin. 1996. Disposition of indinavir, a potent HIV-1 protease inhibitor, after an oral dose in humans. Drug Metab. Dispos. 24:1389-1394.

3. Barry, M., S. Gibbons, D. Back, and F. Mulcahy. 1997. Protease inhibitors in patients with HIV disease. Clinically important pharmacokinetic considerations. Clin. Pharmacokinet. 32:194-209.

4. Bragman, K. 1996. Saquinavir: an HIV protease inhibitor. Adv. Exp. Med. Biol. 394:305-317.

5. Carpenter, C. C., A. M. Fischl, S. M. Hammer, S. M. Hirsch, D. M. Jacobsen, D. A. Katzenstein, J. S. G. Montaner, D. D. Richman, S. M. Saag, R. T. Schooley, A. M. Thompson, S. Vella, P. G. Yeni, and P. A. Volberding. 1998. Antiretroviral therapy for HIV infection in 1997: updated recommendations 
of the International AIDS Society-USA Panel. JAMA 277:1962-1969.

6. Carpenter, C. C., A. M. Fischl, S. M. Hammer, S. M. Hirsch, D. M. Jacobsen, D. A. Katzenstein, J. S. G. Montaner, D. D. Richman, S. M. Saag, R. T. Schooley, A. M. Thompson, S. Vella, P. G. Yeni, and P. A. Volberding. 1998. Antiretroviral therapy for HIV infection in 1998: updated recommendations of the International AIDS Society-USA Panel. JAMA 280:78-86.

7. Chiba, M., M. Hensleigh, and J. H. Lin. 1997. Hepatic and intestinal metabolism of indinavir, an HIV protease inhibitor, in rat and human microsomes. Major role of CYP3A4. Biochem. Pharmacol. 53:1187-1195.

8. Deeks, S. G., J. D. Barbour, J. N. Martin, S. M. Swanson, and R. M. Grant. 2000. Sustained CD $4+$ T cell response after virologic failure of protease inhibitor-based regimens in patients with human immunodeficiency virus infection. J. Infect. Dis. 181:946-953.

9. Denissen, J. F., B. A. Grabowski, K. M. Hohnson, A. M. Buko, D. J. Kempf, S. B. Thomas, and B. Surber. 1997. Metabolism and disposition of the HIV-1 protease inhibitor ritonavir (ABT-538) in rats, dogs and humans. Drug Metab. Dispos. 25:489-501.

10. Fitzsimmons, M. E., and J. M. Collins. 1996. Selective biotransformation of the human immunodeficiency virus protease inhibitor saquinavir by human small-intestinal cytochrome P4503A4: potential contribution to high firstpass metabolism. Drug Metab. Dispos. 25:256-266.

11. Flexner, C. 1998. HIV-protease inhibitors. N. Engl. J. Med. 338:1281-1292.

12. Hirsch, S. M., B. Conway, R. T. D'Aquila, V. A. Johnson, F. Brun-Vezinet, B. Clotet, L. M. Demeter, S. M. Hammer, D. M. Jacobsen, D. R. Kuritzkes, C. Loveday, J. W. Mellors, S. Vella, and D. D. Richman. 1998. Antiretroviral drug resistance testing in adults with HIV infection: implications for clinical management. International AIDS Society-USA Panel. JAMA 279:19841991.

13. Lacy, M. K., and K. P. Abriola. 1996. Indinavir: a pharmacologic and clinical review of a new HIV protease inhibitor. Conn. Med. 60:723-727.

14. Lazdins, J. K., J. Mestan, G. Goutte, R. M. Walker, G. Bold, G. Capraro, and T. Klimkait. 1997. In vitro effect of $\alpha_{1}$-acid glycoprotein on the anti-human immunodeficiency virus (HIV) activity of the protease inhibitor CGP 61755: a comparative study with other relevant HIV protease inhibitors. J. Infect. Dis. 175:1063-1070.

15. Lea, A. P., and D. Faulds. 1996. Ritonavir. Drugs 52:541-546.

16. Markowitz, M., M. Conant, A. Hurley, R. Schluger, M. Duran, J. Peterkin, S. Chapman, A. Patick, A. Hendricks, G. J. Yuen, W. Hoskins, N. Clendeninn, and D. D. Ho. 1998. A preliminary evaluation of nelfinavir mesylate, an inhibitor of human immunodeficiency virus (HIV)-1 protease, to treat HIV infection. J. Infect. Dis. 177:1533-1540.
17. Moyle, G. J., M. Youle, C. Higgs, J. Monaghan, W. Prince, S. Chapman, N. Clendeninn, and M. R. Nelson. 1998. Safety, pharmacokinetics, and antiretroviral activity of the potent, specific human immunodeficiency virus protease inhibitor nelfinavir: results of a phase I/II trial and extended follow-up in patients infected with human immunodeficiency virus. J. Clin. Pharmacol. 38:736-743.

18. Patick, A. K., H. Mo, M. Markowitz, K. Appelt, B. Wu, L. Musick, V. Kalesh, S. Kaldor, S. Reich, D. Ho, and S. Webber. 1996. Antiviral and resistance studies of AG1343, an orally bioavailable inhibitor of human immunodeficiency virus protease. Antimicrob. Agents Chemother. 40:292-297.

19. Powderly, W. G., A. Landay, and M. M. Lederman. 1998. Recovery of the immune system with antiretroviral therapy: the end of opportunism? JAMA 280:72-77.

20. Ren, S., and E. J. Lien. 1998. Development of HIV protease inhibitors: a survey. Prog. Drug Res. 51:1-31.

21. Touw, D. J. 1997. Clinical implications of genetic polymorphisms and drug interactions mediated by cytochrome P-450 enzymes. Drug Metab. Drug Interact. 14:55-82.

22. Vanhove, G. F., H. Kastrissios, J.-M. Gries, D. Verotta, K. Park, A. C. Collier, K. Squires, L. B. Sheiner, and T. F. Blaschke. 1997. Pharmacokinetics of saquinavir, zidovudine, and zalcitabine in combination therapy. Antimicrob. Agents Chemother. 41:2428-2432.

23. Vella, S., and M. Floridia. 1998. Saquinavir. Clinical pharmacology and efficacy. Clin. Pharmacokinet. 34:189-201.

24. Volberding, P. A., and S. G. Deeks. 1998. Antiretroviral therapy for HIV infection: promises and problems. JAMA 279:1343-1344.

25. Welling, P. G. 1997. Metabolite pharmacokinetics, p. 259-269. In P. G. Welling (ed.), Pharmacokinetics-process, mathematics, and applications, 2nd ed. ACS Professional Reference Book. American Chemical Society, Washington, D.C.

26. Wu, E., T. Sandoval, K. Zhang, H. Grettenberger, B. Hee, C. Lee, S. Webber, and B. Shetty. 1998. Cytochrome P450 isoforms involved in the metabolism of nelfinavir mesylate, an HIV-1 protease inhibitor. ISSX Proc. 13:110.

27. Wu, E. Y., J. M. Wilkinson II, D. G. Naret, V. L. Daniels, L. J. Williams, D. A. Khalil, and B. V. Shetty. 1997. High-performance liquid chromatographic method for the determination of nelfinavir, a novel HIV-1 protease inhibitor, in human plasma. J. Chromatogr. B 695:373-380.

28. Zhang, K., B. Kerr, B. Hee, R. Talaat, L. Moger, B. Shetty, and S. Webber. 1998. Biotransformation of nelfinavir, a potent HIV protease inhibitor, in healthy human subjects. ISSX Proc. 13:112. 